\title{
THE ROLE OF MUSIC IN TREATING DYSLEXIA IN CHILDREN
}

\author{
Amina Mohamed EMARA *
}

Faculty of Specific Education, Cairo University, Egypt

\begin{abstract}
Learning is a method through which changes in behavior occur resulting from experience and practice, it is present and the survival of life remains, and for that it is necessary to search for the difficulties facing the learning process and know their causes so that we can overcome them, because everyone who learns faces difficulties or A problem when acquiring a new skill or information or when trying to solve a difficult and complex question or problem, and for this reason, the field of learning difficulties is one of the fields that have occupied the interest of many researchers and that is the result of the increasing interest of parents and educators about the problem of learners with learning difficulties Those who suffer from educational and behavioral problems, although they do not suffer from any apparent disability (such as mental, auditory or visual impairment). Rather, they are characterized by being of average or above average intelligence, meaning that they suffer from various difficulties and due to the effects and implications of these difficulties on Students in particular, and on the educational process in general, it is necessary to address this phenomenon, as the importance of this study lies in the increasing need for studies in the field of learning difficulties that fall into academic problems in the various educational approaches that pose a challenge.

Keywords

Role, Music, Treating, Dyslexia, Children.
\end{abstract}

\section{Introduction}

Two specializations in the field of education, and accordingly, the multiplicity and difference of these difficulties or problems that children with learning difficulties show as a homogeneous group, the research scientists made the classification of learning difficulties in order to facilitate the process of studying this phenomenon and suggest appropriate diagnostic and treatment methods for each group, as there are many classifications for this Difficulties Some of them classify them as developmental difficulties (such as attention and perception disorders) and academic difficulties (such as reading, writing, and arithmetic disorders).

\section{Research problem:}

Reading is one of the most important means of gaining knowledge and obtaining information, and it is a basic means, culture and coexistence with society, and reading is the ability of a person to translate the symbols he sees into sounds, then translate those sounds into meaningful words, and here language skills are used. On a specific brain activity, and this activity does not work in the same way and is equally effective with children who suffer from Dyslexia, reading depends on both eyes and ears so that the reading process can be done in a proper way, and dyslexia disorder is related to the child's inability to communicate and Expression where he suffers from difficulty in understanding ideas despite being smart and creative children in many fields of arts such as (drawing - sculpture - music). Therefore, the researcher found that it is

\footnotetext{
* Corresponding author: fose@cu.edu.eg
} 
necessary to use music as an aid in treating this disorder because music has always an effective role in treating Many disabilities and use them as a treatment for the permanent distraction of attention in these children, and to reduce the hyperactivity associated with this disorder and increase the restraint so that he can follow the educational movement with his peers from the children.

\section{Previous studies:}

- A study entitled: Learning difficulties of a sample of primary school students in the United Arab Emirates, a survey study - Faisal Al-Zarar in 1991 AD.

This study aimed at identifying the percentage of students who suffer from learning difficulties, determining the percentage of developmental difficulties and academic difficulties in the Arabic language and arithmetic, knowing the difference between the sexes in the prevalence rate, and preparing a guide for learning difficulties to assist teachers.

The study sample consisted of 500 students and A student of the only elementary stage in the United Arab Emirates, and the study tools consisted of the illustrated intelligence test.

The researcher also designed a teacher's guide to identify developmental and academic learning difficulties among primary school students and the most important results of the study were:

1. The total number of students who suffer from learning difficulties by $13.7 \%$ of the sample size.

2. Learning difficulties in arithmetic came in the first place. The prevalence rate among males was $(9-8)$.

- A study entitled: The extent of variation in the prevalence of mathematics learning difficulties by exchanging some classification variables among elementary school students in the State of Kuwait - Sudan Hamad Al Mukhlis Al Zoubi 2008 AD.

- This study aimed to identify the prevalence of mathematics learning difficulties among primary school pupils in the State of Kuwait, and whether this percentage differs in different educational districts, grades, and gender, as well as early detection among those with mathematics learning difficulties.

This study has been applied to A random sample of 1161 male and female students from the third and fifth primary grades, $48 \%$ for the third grade and $52 \%$ for the fifth grade, as well as $50 \%$ males and 50\% females in the 2006-2007 school year.

And the study found the following results: The final percentage of people with learning difficulties in mathematics was $13.4 \%$ of primary school students in the State of Kuwait. There are no statistical differences in the prevalence rates and learning difficulties of mathematics among students of the only elementary stage in both groups, males and females. 
The prevalence of those with learning difficulties among males was $13.3 \%$ and females $13.6 \%$. This result was explained by the prevalence of learning difficulties in mathematics that does not differ according to gender and that the apparent generalization between males and females (10-89).

\section{Commentary on the previous studies:}

The two studies share one of the learning difficulties in reading and arithmetic, and each study focused on a specific aspect. There are those who focused on the psychological aspect and there are those who focused on the gender factor in terms of being male and female. As for the subject of the current study, it aims to identify dyslexia, which is one of the learning difficulties and its relationship to the low level of academic achievement.

\section{Some foreign studies) that dealt with dyslexia:}

- In $1881 \mathrm{AD}$, (Uzo Aldebirkan) identified patients, and the term dyslexia was coined later in 1887 AD by (Rudolf Berlin) who is an ophthalmologist working in Stau, Germany.

-In 1896 AD,(George Pringle Morgan) published a description of the disorder of learning to read in the British Medical Journal, "Congenital Failure to Read" In the period from 1890 AD to early $1900 \mathrm{AD}$, James Henschlord published a series of articles in medical journals where he described similar cases of congenital ill readability, and In his book Congenital Unable to Read 1917 AD, Henschlord emphasized that the main deficit was visual memory of words and letters, and described some symptoms, including letter setbacks and difficulties with spelling, reading and comprehension.

-In 1925, Samuel T. Orton determined that there were symptoms unrelated to brain damage that would make learning to read difficult. Where Orton described in his theory of (inverted vision) affected individuals after reading that they had difficulty in linking the visual shapes of words with their spoken images, so the teacher (Gillesingham) developed a worm educational intervention using simultaneous multi-sensor teaching. Paris, 1951 AD) to further afield, as this phenomenon linked the movement to sight, as it disappears when the space between letters increases and reading turns into spelling, and it also explained the ability to read in women.

A new hypothesis in the 1970s showed that dyslexia stems from a deficit in phonological processing or difficulty recognizing that spoken words are a problem in separate phonemic units where affected individuals have difficulty connecting these sounds.

Along with the visual letters that compose the written words (604: 890-1), the most important studies have indicated the importance of vocal awareness.

- In 1979, Glabord, Cumber and Glaborda mentioned notes from an examination of some of the anatomy of some people who had suffered from introspection and reading, as their study 
reported anatomical abnormalities in the language center in the child's brain resulting from incomplete growth from the sixth month of fetal brain development.

In 1993, Castles and Coulthert described developmental dyslexia as two distinct and diffuse types using subtypes of surface and phonological dyslexia.

- In 1994, from autopsy samples made by Glaborda and others, it was reported that the abnormal auditory processing in dyslexic people suggests that accompanying anatomical abnormalities may be present in the auditory system.

- In 2003 Collins Rorrock concluded that current models of the relationship between the brain and dyslexia generally focus on some form of retardation or retardation of the brain.

In 2007 Lettin et al. Sought to establish a link between neurological and genetic discoveries and reading disorder.

- In 2008 Hayim described the cognitive subtypes of Dyslexia and how to compare different subsets of sufferers (07-17).

\section{Theoretical framework:}

Definition of Dyslexia: According to the World Federation of Neurology, Dyslexia can be defined as a disorder that manifests itself in the difficulty of learning to read despite the availability of traditional instructions, sufficient intelligence, and appropriate social and cultural opportunity, as it follows a substantial cognitive impairment of a healthy origin.

We must point out that students with Dyslexia have a very normal or above-normal level of intelligence, but most of them are creative people in other fields, which makes Dyslexia deserves to be called a hidden handicap. Mental or sensory and not related to cultural or environmental factors or unwillingness to study, and the IQ of the person suffering from this disorder is normal or above normal.

Dyslexia is also known as a persistent and severe difficulty in learning to read and acquiring its skill for intelligent children who live in a normal social environment. This difficulty is characterized by its persistence in the long run as it is not diagnosed until at least six months have passed from the start of learning the written language and it affects 1 to $8 \%$ of children of school age (97-13).

\section{The difference between Dyslexia and delayed reading:}

It is necessary to distinguish between both symptoms because there are many differences between dyslexia disorder and cases of delay or backwardness in reading. The scientist Rotter Weil conducted a study on two samples, one of which was diagnosed as a general backwardness in reading and can be summarized as follows: (32-2)

1) Dyslexia or dyslexia is more common among males, unlike reading retardation, so it is of 
both sexes.

2) Neurological disabilities are more prevalent among late reading classes.

3) Progress in reading and spelling is slower in the eyes of children with difficulty reading compared to late children (4-15).

The most important manifestations of dyslexia:

First: We must emphasize that there is no correlation between this phenomenon with IQ, which explains the shock of parents when they discover that their son suffers from reading difficulties, even though he was showing signs of natural or even supernatural intelligence, which can be summarized in:

1) Linguistic manifestations. Being late or not speaking clearly or mixing letters, words or sentences, for example:

Flip a portion of the word and read (bant) instead of (plant).

- Also (quava) instead of (fruit)

- Deleting an entire syllable from the word as if he was reading the word (house) instead of (houses) (and girl) instead of (girls)

- Reverse the letter positions of the word either in advance or delay, such as reading (heart) instead of - from (before) (and slave) instead of (after) and (Faras) instead of (Safar).

Deleting some words and parts of the read word, for example the phrase (I traveled by plane) the student might read (traveled by plane)

- Adding some words that are not in the original text to the sentence or some syllables or letters to the read word, for example the word (I traveled by plane) may be read here I traveled by plane to America)

Repeating some words more than once without justification, for example, he may read (the mother washed the clothes) and say (the mother washed) or (washed the clothes).

Replacing some words with others that may carry some of their meaning. For example, he may read the word (high) instead of (elevated) or (students) instead of (students).

Weakness in distinguishing between vowels, as he may read the word (ful) and say (phil)

- Difficulty locating in the text, as it gets confused when moving from the end of the line to the beginning of the next one, stopping for a while and looking from where it starts again

2) Manifestations related to the child's daily activities: Many daily habits and behaviors that the child performs that may indicate his suffering from dyslexia, such as:

- How to deal with things, such as the difficulty of keeping them in his hand and the difficulty of coordination in the actions he performs such as holding balls, bending them, or throwing them normally. 
Difficulty performing some tasks such as wearing clothes normally, tying shoes and using buttons.

Impaired concentration when hearing stories (212-4)

- Dyslexia may also be associated with other manifestations such as poor handwriting, deviation from the line, difficulty coordinating letters, and it can also be associated with dysarthria, dysarthria and other learning difficulties. Despite the appearance of all these signs, it must be shown to the specialist doctor in order to diagnose the condition well and determine the degree of injury.

\section{Physiological manifestations:}

A child with dyslexia is characterized by a different brain structure than a normal child, which leads to ineffectiveness in the connection between the left and right parts of the brain. Its counterpart in other children, and the language area of the brain in people with dyslexia or reading disability in the left hemisphere is always smaller or less in the number of cells in the same frame always, and it has been observed that the electrical activity in the left hemisphere of the brain among those suffering from dyslexia differs fundamentally.

For those who do not suffer from this difficulty (5-11). Most researchers rely on multiple tests to exclude other possible causes of reading difficulties, such as cognitive impairment or physiological causes such as problems with vision or hearing, and evaluation tests are also adopted for the child's ability to read, such as the rapid recognition test to test short-term memory, sequencing skills, phonetic discrimination tests, and various intelligence tests and these Tests and others enable specialists to comprehensively judge the child's condition and determine the degree and type of injury (816-14).

\section{Results:}

1- Determining the most important difficulties that hinder learning, which is dyslexia, a phenomenon that many educators and parents are unaware of, relying on this failure on the child despite being creative in other areas.

2- Opening the field for new research studies to confront the problems of learning difficulties and treat them appropriately to serve the production process.

3- Music is an essential and always helpful element in many treatments for learning difficulties in the learning process, because music has a tangible effect on treatment, especially as it calms the child and helps him focus and remove the diaspora component from him, which is one of the foundations of dyslexia.

4- Identify the individual differences between children and help those with learning difficulties individually temporarily until they are merged with the class members again without 
embarrassment, by doing reading exercises with music and audible visuals from two sections so that the child can see and hear the reading, which results in improvement Fits well.

5- Demonstrate the importance of music in treating dyslexia, attention deficit and hyperactivity associated with this disorder, because of the benefits of music in treating multiple academic and developmental deficiencies, and the success of music in treating most programs and making use of it in research and application in educational and therapeutic institutions.

6- This study is considered one of the interdisciplinary studies that integrate psychological knowledge with musical knowledge, with the aim of obtaining results acceptable to many disabilities that prevent the educational process.

\section{Recommendations:}

1- The necessity for teachers to use music as an aid in treating dyslexia as one of the most important tools for communicating information and feeling together.

2- The necessity of conducting more scientific research on this important disorder, which has a great impact on the learning process, to help this group to overcome these difficulties.

3- The necessity of designing musical programs aimed at treating dyslexia in an appropriate manner and applying it to schools, especially in the elementary stage.

4- Using educational aids and musical activities aimed at overcoming the problems of dyslexia, as it is one of the learning difficulties that most parents are ignorant of.

5- Preparing teaching methods based on the participation of a teacher of any subject and a teacher of musical education, employing music in the service of the educational process and not concerned with being entertainment only for children.

6- Providing some programs that design audiobooks, the basis of which are repeated school songs and songs by simple tunes with repetition of some melodic sentences and not putting jumps until the dyslexia student can use them to draw attention to the loss of the diaspora component that is characteristic of it.

\section{References}

1- Ahmed Abdel-Karim Hamzah Psychology of Dyslexia - House of Culture for Publishing and Distribution - 1st Edition - Amman - 2008 AD.

2- Jamal Mithqal Mustafa Al-Qasim - Fundamentals of Learning Difficulty - Safaa House for Publishing and Distribution - 1st floor - Amman - 2000 AD.

3- Fouad El-Bahi El-Sayed, the psychological foundations of growth - Dar Al-Fikr Al Arabi for Publishing and Distribution - 1st Edition, Egypt - 1956 AD.

4- Zayat Fathi - Mentally Superior with Learning Difficulties - Diagnostic and Treatment Issues

- Universities Publishing House. 1 - Cairo - 2002 AD. 
5- Salma Muhammad Melhem - Learning Difficulties - Dar Al Masirah for Publishing and Distribution - 1st floor - Amman - 2002 AD.

6- Hana Ibrahim Sundafly from Learning Difficulties - Dar Al-Nahda for Publishing and Distribution - Beirut - 2008.

7 - Waqf Radi - theoretical and applied learning difficulties - Jordan 2003.

8- Faisal Al-Zarar - learning difficulties of a sample of primary school students in the United Arab Emirates - PhD thesis - Emirates - 1991 AD.

9- Sudan Hamad Al Mukhlis Al Zaabi The extent of the variation in the prevalence of mathematics learning difficulties with the variation of some taxonomic stimuli among elementary school students in the State of Kuwait, PhD thesis - State of Kuwait 2008.

10- Stanovich - KE - (1988) "Explaining the differences between the dyslexia and the gardenvariety poor reader the phonological care variable difference model." Journal of learning Disabilities. $21(10)=590-604$

11- Developmental dyslexia in adulty a research review. National research and development center for adult literacy and 147 - 133 numeracy. 2004-05.

12- Richardson U, Leppanen PH leiwo 12 - melyytinen H (2003). "speech perception of infants with high familial risk fon dyslexia differ at the age of 6 months" Developmental Neuropsychology 23 (3): 385-97.

13- Pennington Bf, lefty DL (2001). Early. Reading development in children at family risk for dyslexia. Child Development 72 (3): 816-833.

14- N. Calvin Deug1 Avignon, thenries DuDeveloppement, 1998: 250-260.

15- Geary. D.C (2006): Dyscalculia at an early age: characteristics and potential in fluence on socio emotional Development center of Excellence for early childhood development geary Dc Montreal qulbec: 520 - 250,

16- Dyslexia and what is the problem, Medicine Magazine, version - Wayback Machine October 2011, reserved.

17- Gulf Children Site with Special Needs. abigexo7 worst 2011

18- as bil obhodl soj zul Jlåbl 1994 www.qulifkd.com

19- vw go wo w so vaikas grese algabll 92012 www.https //. Alukah: net

20- Muhammad Abdul Rahman AL SHAFEI, THE IMPACT OF THEATRICAL PERFORMANCES AND THEIR IMPACT ON FORMING COMMUNITY CULTURE “AN ANALYTICAL STUDY", International Journal of Humanities and Language Research, Vol. 2, No. 2, 2019, pp. 33-37.

21- Reham SHALABY, THE CREATIVE ROLE OF PLASTIC ARTS IN THE FACE OF 
DISCRIMINATION AND VIOLENCE AGAINST WOMEN, International Journal of Humanities and Language Research, Vol. 2, No. 2, 2019, pp. 1-8.

22- Wissam Hassan HASHEM, THE DESIGN PERFORMANCE OF INTERNAL SPACES AND ITS RELATIONSHIP TO THE SOCIAL VARIABLE: BAGHDAD CAFES ARE A MODEL, International Journal of Humanities and Language Research, Vol. 2, No. 2, 2019, pp. 9-19.

Received: March 4, 2020

Accepted: May 21, 2020 